\title{
Characterizing Unsafe Sexual Behavior among Factory Workers in the Context of Rapid Industrialization in Northern Vietnam
}

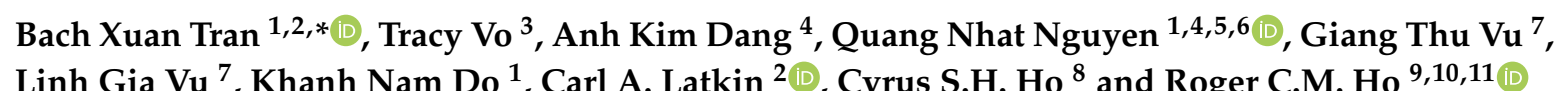
Linh Gia Vu ${ }^{7}$, Khanh Nam Do ${ }^{1}$, Carl A. Latkin ${ }^{2}{ }^{(}$, Cyrus S.H. Ho ${ }^{8}$ and Roger C.M. Ho ${ }^{9,10,11}$

1 Institute for Preventive Medicine and Public Health, Hanoi Medical University, Hanoi 100000, Vietnam; quang.n.nguyen@alumni.duke.edu (Q.N.N.); donamkhanh@hmu.edu.vn (K.N.D.)

2 Bloomberg School of Public Health, Johns Hopkins University, Baltimore, MD 21205, USA; carl.latkin@jhu.edu

3 Department of Sociomedical Sciences, Mailman School of Public Health, Columbia University, New York, NY 10027, USA; tracy.vo@columbia.edu

4 Institute for Global Health Innovations, Duy Tan University, Da Nang 550000, Vietnam; kimanh.ighi@gmail.com

5 Vaccine Research Center, National Institute of Allergy and Infectious Diseases, National Institutes of Health, Bethesda, MD 20892-9806, USA

6 UnivLyon, Université Claude Bernard Lyon 1, 69100 Villeurbanne, France

7 Center of Excellence in Evidence-based Medicine, Nguyen Tat Thanh University, Ho Chi Minh City 700000, Vietnam; giang.coentt@gmail.com (G.T.V.); linh.coentt@gmail.com (L.G.V.)

8 Department of Psychological Medicine, National University Hospital, Singapore 119074, Singapore; cyrushosh@gmail.com

9 Center of Excellence in Behavioral Medicine, Nguyen Tat Thanh University, Ho Chi Minh City 700000, Vietnam; pcmrhcm@nus.edu.sg

10 Department of Psychological Medicine, Yong Loo Lin School of Medicine, National University of Singapore, Singapore 119228, Singapore

11 Institute for Health Innovation and Technology (iHealthtech), National University of Singapore, Singapore 119077, Singapore

* Correspondence: bach.ipmph@gmail.com; Tel.: +84-982228662

Received: 23 September 2019; Accepted: 3 December 2019; Published: 12 December 2019

\begin{abstract}
Industrial workers or factory workers, especially migrant workers, have been found to be vulnerable populations at risk of sexually transmitted infections (STIs). However, there has been a gap in literature regarding health behaviors of migrant factory workers. We conducted a cross-sectional study among 230 factory workers in Hanoi and Bac Ninh cities in Northern Vietnam from July to September 2018 to identify sexual risk practices and related factors among migrant and nonmigrant factory workers. Information collected regarding sexual behavior included the number of sexual partners in the previous 12 months and whether they used condoms in their last sexual intercourse. Two-thirds of participants reported having no sexual activity in the last 12 months, and there was a low percentage of participants using condoms in their last sexual intercourse. Being female, living with spouses/partners, and being a nonimmigrant had a negative association with the lack of using condoms in the last sexual intercourse with casual partners/sex workers, as opposed to having mobility and self-care problems and identifying as a binge drinker. Therefore, workplace-based prevention programs focusing on providing tailored sexual health education and promoting condom use among industrial workers, especially those who are immigrant or migrant workers, in Vietnam should be emphasized.
\end{abstract}


Keywords: industrial worker; factory worker; sexually transmitted infections; condom use; sexual risk behavior; Vietnam

\section{Introduction}

The majority of migrated people in Vietnam are young adults with middle-level education status and they migrate to more urban areas mainly for employment reasons [1]. Previous studies indicated that moving to a new workplace may expose these migrant workers to new social networks, ideas, behaviors, or even socially isolated situations that could alter their lifestyle choices, including engaging in sexual risk behaviors [2]. Migrant workers are often subjected to harassment, exploitation, and violence, which may lead to poor health outcomes, and they may also face barriers to health care in the host country, such as limited or lack of health insurance and entitlement to statutory health care [3]. Migration, mobility, and family separation all relate to having a greater sense of anonymity, which might further facilitate unsafe behavioral changes, such as hazardous drinking and high-risk sexual practices [4,5]. In fact, among mobile worker populations in selected provinces in Vietnam in 2002, human immunodeficiency virus (HIV) prevalence was relatively low except among border traders in An Giang and Dong Thap provinces, which saw 2.5\% and 2.1\% prevalence, respectively [6]. Though this study looked at a limited group of mobile workers, it is suggested that the mobility of sex work across the border contributed to the high prevalence of HIV among border traders. In other low-middle-income countries like Vietnam, such as India and Thailand, factory workers and male migrant workers, respectively, are among the most vulnerable populations to HIV/AIDS (acquired immune deficiency syndrome) and other sexually transmitted infections (STIs) [7,8]. Migrant workers generally are at greater risk of heterosexual HIV transmission due to their demographic characteristics, such as lack of access to HIV treatment and prevention, unstable family and work situations, and access to sex workers [9].

Previous studies have found that risk perception and knowledge of consequences of unprotected sex, including HIV/AIDS, are generally low among younger migrant factory workers. For instance, in a study done in Nepal, it was reported that $90.2 \%$ of males and $41.7 \%$ of females who had nonregular sexual partners perceived having no risk of HIV/AIDS [10]. Another study conducted among migrant workers in manufacturing, construction, accommodation/catering, domestic service, wholesale/retail, and entertainment fields in China revealed that the majority of them did not use condoms while engaging in sexual intercourse, and about two-thirds of participants never or only occasionally used condoms with their casual extramarital partners within the last 12 months [11]. Studies among workers in Bangladesh, India, and Jordan also saw similar results of high levels of risky sexual practices $[4,7,12]$. Furthermore, a previous study conducted in Hanoi, Vietnam, found a considerable knowledge gap in HIV/AIDS prevention among male migrant workers [13]. Lack of HIV knowledge and a variety of essential health care resources were highlighted particularly among vulnerable groups, including those who were mostly low-income, employed outside of labor contracts, and unregistered for residence [13].

In the context of Vietnam, the country is rapidly transitioning into an industrial country with an increasing number of workers [14]. However, the provisions of protecting workers' rights in using universal health coverage and accessing health services are still limited for both those who are outside labor contracts and within. Moreover, there is little evidence of literature on the high-risk sexual practices among factory workers and the underlying factors of such activities in Vietnam. Therefore, we aimed to identify the risk of sexual practices as well as related factors among factory workers in Hanoi and Bac Ninh, which are the two major cities with an increasing rate of geographic labor mobility. These findings may fill in the gap of HIV/AIDS and STI prevention of industrial workers and are intended to promote the national policy to meet the health care needs of this critical working population. 


\section{Materials and Methods}

\subsection{Study Design and Sampling}

We carried out a cross-sectional study in three factories manufacturing electronics and vehicle accessories from July to September 2018 in Hanoi and Bac Ninh. In each factory, there were approximately 6000, 2000, and 1150 workers.

We used the convenient sampling technique to select participants of the study. A total of 230 workers were recruited in the study based on the following eligibility criteria: (1) Being 18 years of age and above; (2) having signed labor contracts; (3) having worked at the factory for at least 6 months; and (4) having the capacity to answer the questionnaire. Workers who were not able to communicate with the interviewers were excluded from the research.

\subsection{Measure and Instruments}

Trained researchers conducted 20-min face-to-face interviews with participants. Briefly, we invited participants into a private working office with restricted access in order to secure their confidentiality. Study purposes, benefits, and drawbacks were clearly introduced before asking participants to join the study. Participants who agreed to take part in the study would sign written informed consent forms.

Data collectors were researchers who had undergone research and ethics training to conduct interviews and collect data. Staff members of the factories were not allowed to participate in the data collection process. We ensured that questionnaires were anonymous by assigning participants a randomized ID number, and any information related to a participant's identity and contact information was not collected during the research process.

A pilot survey was conducted prior to the data collection to examine the feasibility of recruitment and identify any needed modifications. There were 20 participants (both male and female with varied ages) involved in the pilot stage. The final structured questionnaire included the following information:

\subsubsection{Socioeconomic Characteristics}

Respondents self-reported information regarding gender, age, educational level, marital status, monthly income, and whether they were living with their families. Information about immigration status, years of work experience, and the number of working hours per day was also collected.

\subsubsection{Sexual Behaviors}

Participants were asked whether they had had sexual intercourse in the last 12 months. Those who answered "yes" were asked to report "how many partners that they had sexual intercourse with in the previous 12 months", including intimate partners, sex workers, and casual partners (receiving and without receiving money). We also asked whether or not they used condoms in their last sexual intercourse with these partners.

\subsubsection{Health Risk Behaviors}

Drinking pattern was examined using the Alcohol Use Disorders Identification Test-Consumption (AUDIT-C) [15]. This tool contained 3 questions with the overall score ranging from 0 to 12 . The higher score of AUDIT-C suggested a greater risk of alcohol dependence. Drinking patterns were also determined. Participants were identified as hazardous drinkers if the total score of AUDIT-C was higher than 4 for males and higher than 3 for females. Binge drinkers were identified as having any positive response to the following question: "How often do you have six or more drinks on one occasion?"

We divided the smoking status of participants into 3 types: Current smokers, former smokers, and never-smokers [16]. A current smoker was an adult who had smoked at least 100 cigarettes in his or her lifetime and had smoked in the last 30 days. The former smoker was identified as an adult who 
had smoked at least 100 cigarettes in his or her lifetime, but had quit smoking at the time of interview. A person who had never smoked, or who had smoked less than 100 cigarettes in his or her lifetime was defined as a never-smoker.

\subsubsection{Health Status}

Health-related quality of life (HRQoL) was assessed by the Vietnamese version of the EQ-5D-5L questionnaire [17]. There were five health aspects that were measured, including mobility, self-care, usual activities, pain/discomfort, and anxiety and/or depression. Each domain was assessed by a Likert scale (no problems, slight problems, moderate problems, severe problems, and extreme problems). Respondents also self-reported their current acute and/or chronic conditions, the number of health problems they had had, and whether they had utilized reproductive health services in the last 12 months.

\subsection{Statistical Analysis}

Data were analysed using STATA 12.0 (Stata Corp. LP, College Station, TX, USA). Socioeconomic characteristics, health risk behavior, and health status were compared between those using and not using a condom in the last sexual intercourse with casual partners and/or sex workers. Generalized estimating equations (GEE) binomial regression was conducted to identify the factors related to not using a condom with casual partners and/or sex workers. GEE was used to control the potential correlation of outcomes between respondents from the same factory, assuming an independent correlation structure. The robust standard errors were estimated, adjusting for the clustering within factories. A $p$-value less than 0.05 was statistically significant.

\subsection{Ethics Approval}

The research protocol was approved by the Institutional Review Board of the Hanoi Medical University (code: 01a-QD/VNCTN).

\section{Results}

Table 1 highlights the demographic characteristics, general health status, and drinking/smoking practices of the participants. The majority of the participants were female $(81.2 \%)$ and about two-thirds of respondents had high school education (61\%). Almost all of the participants $(96.5 \%)$ had a spouse or partner. The mean monthly income was $\$ 282.40$ ( $\mathrm{SD}=106.5$ ), and the mean working time was 9.8 years $(\mathrm{SD}=3.7)$. There were $16.6 \%$ and $15.7 \%$ of participants who were considered hazardous drinkers and binge drinkers, respectively. The majority of participants were never-smokers (85.5\%) and had acute or chronic conditions ( $84.2 \%)$. Approximately half of participants had used reproductive health services $(45.0 \%)$. 
Table 1. Demographic characteristics, general health status, and behaviors of participants ( $\mathrm{n}=230$ ).

\begin{tabular}{|c|c|c|}
\hline Characteristics & $\mathbf{n}$ & $\%$ \\
\hline Gender (Female) $(n=230)$ & 186 & 81.2 \\
\hline \multicolumn{3}{|l|}{ Education attainment $(n=228)$} \\
\hline Under high school & 17 & 7.5 \\
\hline High school & 139 & 61.0 \\
\hline Above high school & 72 & 31.5 \\
\hline \multicolumn{3}{|l|}{ Marital status $(n=230)$} \\
\hline Single & 8 & 3.5 \\
\hline Having spouse/partner & 222 & 96.5 \\
\hline \multicolumn{3}{|l|}{ Currently living with $(\mathrm{n}=228)$} \\
\hline Parents & 115 & 50.4 \\
\hline Wife/husband & 187 & 82.0 \\
\hline Children & 139 & 61.0 \\
\hline Brothers/sisters & 18 & 7.9 \\
\hline Relatives & 2 & 0.9 \\
\hline Colleague & 2 & 0.9 \\
\hline Immigrants/migrant workers $(\mathrm{n}=229)$ & 117 & 51.1 \\
\hline \multicolumn{3}{|l|}{ Having problems in $(n=230)$} \\
\hline Mobility & 76 & 34.1 \\
\hline Self-care & 7 & 3.2 \\
\hline Usual activities & 73 & 32.7 \\
\hline Pain/Discomfort & 132 & 61.4 \\
\hline Anxiety/Depression & 135 & 62.8 \\
\hline Having acute and/or chronic conditions $(n=222)$ & 187 & 84.2 \\
\hline $\begin{array}{l}\text { Using reproductive health service in the last } 12 \\
\text { months }(n=220)\end{array}$ & 99 & 45.0 \\
\hline Hazardous drinking $(\mathrm{n}=223)$ & 37 & 16.6 \\
\hline Binge drinking $(n=223)$ & 35 & 15.7 \\
\hline \multicolumn{3}{|l|}{ Current smoking status $(n=214)$} \\
\hline Never-smokers & 183 & 85.5 \\
\hline Former smokers & 14 & 6.6 \\
\hline \multirow[t]{2}{*}{ Current smokers } & 17 & 7.9 \\
\hline & Mean & SD \\
\hline Age & 31.7 & 4.5 \\
\hline Monthly income (USD) & 282.4 & 106.5 \\
\hline Years of experience & 9.8 & 3.7 \\
\hline Working hour per day & 8.3 & 0.9 \\
\hline Number of acute and/or chronic conditions & 1.8 & 1.7 \\
\hline
\end{tabular}

Table 2 shows that, among the approximately two-thirds of participants who had sex in the last 12 months $(67.8 \%), 64.8 \%$ had one sex partner. Almost half of the respondents reported using condoms when they had sex with their spouse/intimate partners in their last sexual intercourse (42.6\%). Among those who had sexual intercourse with sex workers, casual partners without receiving money, and casual partners while receiving money, 38.3\%, 39.3\%, and 43.9\%, respectively, reported using condoms in their last sexual intercourse. 
Table 2. Sexual behaviors in the last 12 months among participants.

\begin{tabular}{|c|c|c|c|c|c|c|c|}
\hline \multirow[t]{2}{*}{ Characteristic } & \multicolumn{2}{|c|}{$\begin{array}{l}\text { Local People } \\
\quad(n=113)\end{array}$} & \multicolumn{2}{|c|}{$\begin{array}{l}\text { Migrants } \\
(n=117)\end{array}$} & \multicolumn{2}{|c|}{ Total } & \multirow[t]{2}{*}{$p$-value } \\
\hline & $\mathbf{n}$ & $\%$ & n & $\%$ & $\mathbf{n}$ & $\%$ & \\
\hline Having sex $(n=224)$ & 71 & 64.6 & 77 & 67.5 & 148 & 66.1 & 0.80 \\
\hline \multicolumn{8}{|c|}{ Number of sex partners (all types) $(n=225)$} \\
\hline None & 20 & 18.2 & 17 & 14.9 & 38 & 16.5 & 0.83 \\
\hline One sex partner & 69 & 62.7 & 76 & 66.7 & 145 & 64.8 & \\
\hline Two sex partners or more & 2 & 1.8 & 1 & 0.9 & 3 & 1.3 & \\
\hline Don't remember & 19 & 17.3 & 20 & 17.5 & 39 & 17.4 & \\
\hline \multicolumn{8}{|c|}{ Using condom in the last sexual intercourse with } \\
\hline Spouse/intimate partners $(\mathrm{n}=214)$ & 47 & 46.5 & 49 & 43.4 & 96 & 44.9 & 0.64 \\
\hline Yes & 47 & 46.5 & 49 & 43.4 & 96 & 44.9 & 0.64 \\
\hline No & 54 & 53.5 & 64 & 56.6 & 118 & 55.1 & \\
\hline \multicolumn{8}{|l|}{ Sex workers $(n=177)$} \\
\hline Yes & 11 & 12.8 & 7 & 7.7 & 18 & 10.2 & 0.15 \\
\hline No & 16 & 18.6 & 10 & 11.0 & 26 & 14.7 & \\
\hline Do not remember & 59 & 68.6 & 74 & 81.3 & 133 & 75.1 & \\
\hline \multicolumn{8}{|c|}{ Casual partners without receiving money $(n=187)$} \\
\hline Yes & 12 & 13.5 & 8 & 8.2 & 20 & 10.7 & 0.44 \\
\hline No & 16 & 18.0 & 16 & 16.3 & 32 & 17.1 & \\
\hline Do not remember & 61 & 68.5 & 74 & 75.5 & 135 & 72.2 & \\
\hline \multicolumn{8}{|c|}{ Casual partners while receiving money $(\mathrm{n}=178)$} \\
\hline Yes & 11 & 12.9 & 6 & 6.5 & 17 & 9.5 & 0.23 \\
\hline No & 11 & 12.9 & 9 & 9.7 & 20 & 11.2 & \\
\hline Do not remember & 63 & 74.1 & 78 & 83.9 & 141 & 79.2 & \\
\hline
\end{tabular}

Table 3 assesses the factors related to not using condoms with sex workers and/or casual partners. Workers who were female, had completed high school education or above, or were living with a spouse/partner were less likely to not use condoms with casual partners or sex workers. By contrast, workers who were immigrants or migrants, considered to be binge drinkers and reported having mobility and self-care problems, were more likely to not use condoms in their last sexual intercourse with casual partners or sex workers.

Table 3. Factors associated with not using a condom with casual partners or sex workers $(\mathrm{n}=208)$.

\begin{tabular}{|c|c|c|c|}
\hline \multirow{2}{*}{ Characteristics } & \multicolumn{3}{|c|}{$\begin{array}{l}\text { Not Using Condom with Casual Partners/Sex } \\
\text { Workers in the Last Sexual Intercourse }\end{array}$} \\
\hline & OR & $95 \% \mathrm{CI}$ & $p$-value \\
\hline \multicolumn{4}{|l|}{ Education (vs. Less than high school) } \\
\hline High school & $0.12 * * *$ & $0.03 ; 0.43$ & 0.00 \\
\hline Immigrants/Migrants (Yes vs. No) & $2.49 * * *$ & $1.60 ; 3.88$ & 0.00 \\
\hline Age & $1.06 * *$ & $1.01 ; 1.11$ & 0.03 \\
\hline \multicolumn{4}{|l|}{ Having problems in } \\
\hline Mobility problems (Yes vs. No) & $2.84^{* * *}$ & $1.36 ; 5.93$ & 0.01 \\
\hline Self-care problems (Yes vs. No) & $4.85^{* * *}$ & $2.48 ; 9.47$ & 0.00 \\
\hline Using reproductive health service in last 12 months (Yes vs. No) & 1.47 & $0.57 ; 3.77$ & 0.42 \\
\hline Hazardous drinking (Yes vs. No) & 0.30 & $0.04 ; 2.09$ & 0.23 \\
\hline Binge drinking (Yes vs. No) & $3.97 * *$ & $1.12 ; 4.15$ & 0.03 \\
\hline \multicolumn{4}{|l|}{ Current smoking status (vs. Never-smokers) } \\
\hline Former smokers & 1.06 & $0.54 ; 2.09$ & 0.87 \\
\hline Current smokers & $0.37 * *$ & $0.15 ; 0.91$ & 0.03 \\
\hline
\end{tabular}

${ }^{* * *} p<0.01,{ }^{* *} p<0.05, * p<0.1$. 


\section{Discussion}

This research is among the few studies that examine the sexual risk practices among factory workers in Northern Vietnam. We reported a low percentage of condom use among the workers in their last sexual intercourse with sex workers and/or casual partners. In addition, we found that being a female worker, living with spouses/partners, and being a local (and not a migrant) worker were negatively associated with no condom usage in the last sexual intercourse with casual partners or sex workers. By contrast, having problems in mobility, having self-care problems, and being a binge drinker were positively associated with a lack of condom usage in the last sexual intercourse with sex workers and/or casual partners. Our results provide evidence supporting the enhanced implementation of critical sexual health interventions for people working in industrial zones in Northern Vietnam.

In this study, we found a low percentage of participants using condoms in their last sexual intercourse with sex workers and/or casual partners. This finding is lower than the result of a previous study in India, which found that nearly $60 \%$ of workers used condoms in their last sexual intercourse with nonspousal partners [7]. However, when compared to the percentages of condom usage among migrant workers and their nonspousal partners in another study in India, our study showed higher percentages of condom usage with nonspousal, unpaid partners, but not with sex workers [18]. Another study done in China showed that returning rural-to-urban migrant workers had an elevated risk of risky sexual behaviors over nonmigrant workers [19], as our study also indicates. In spite of Vietnam's large scale " $100 \%$ condom use program", which directly promoted the use of condoms especially in sex work as part of the National Strategy on HIV/AIDS Prevention and Control [20], our findings show that a high percentage of factory workers engaged in high-risk sexual activities. This is concerning given that unprotected sex is considered one of the main risks of infecting HIV via heterosexual intercourse [21]. Further analysis of factors underlying condom use preferences among industrial workers may provide important insight into developing more effective promotion of condom use in this high-risk population.

Our study suggested that female workers and those who were living with spouses or partners were less likely to not use condoms in their last sexual intercourse. First, in terms of marital status, a previous study done in Chiang Mai, Thailand, showed that factory workers without a cohabiting partner were more likely to engage in higher-risk sexual activity, as compared to those with a cohabiting partner [21]. Moreover, migrant workers living alone were at greater risk of sexual behaviors potentially exposing them to HIV transmission [22,23]. Regarding the association between being a female worker and condom use, it should be noted that most of our study participants were female, which could have impacted our results [24,25]. In fact, a woman's judgment of her own ability to negotiate and practice a given sexual behavior has been found to be a strong predictor for condom use in the last sexual intercourse with her husband [26]. Similarly, another study found that the more a female student perceived that women were subordinate to men, the lower a female student's self-efficacy related to sexual communication, which involves communicating preference for condom use with their partners [27]. Moreover, a study conducted among factory workers in Chiang Mai, Thailand, revealed that sexual behaviors are normalized among men, but not women among Chiang Mai factory workers [21]. Lastly, a high proportion of female migrant workers in the industrial parks in Vietnam considered condoms as a contraceptive method as well as preventing sexually transmitted diseases [28].

In contrast, we found that migrant and immigrant workers had higher odds of not using condoms in the last sexual intercourse with sex workers and/or casual partners. Sexual behaviors of migrants and immigrants often changes upon moving, and the feeling of anonymity in a new region or country may increase the likelihood of participating in risky sexual activities, such as alcohol abuse, multiple sex partners, or having sexual intercourse with commercial sex workers [11,29]. Studies in the past further indicated that such high-risk sexual activities might be the social-psychological characteristics of some migrant workers. Specifically, migrant workers, who are often forced into physically demanding jobs with poor living conditions and little to no benefits while having to live apart from their spouses and families, may develop new sexual relationships and engage in high-risk behaviors that may 
increase the probability of HIV infection [30,31]. For example, Chen et al. emphasized the relationship between alcohol use risk and a series of sexual risk behaviors (early sexual debut, not utilizing condoms, and having sex under the impact of alcohol) in China, but saw this among female sex workers [32]. Furthermore, as found in our study, the co-occurrence of alcohol use and unprotected sex has been reported in other settings [33-36]. Aside from sexual risk behaviors and other risky behaviors, migration status remained significant even when we accounted for certain mental health status indicators, such as anxiety and depression and having self-care problems. This suggests that factors related to a worker's identity as a migrant or immigrant affects condom use and other unsafe sexual behaviors.

In addition, health status was another factor we saw associated with low condom use. Agreeing with previous findings [37], we found that those who reported having mobility issues or self-care problems had higher odds of not using condoms with casual partners and/or sex workers. Our study's results with health status indicators were similar to those of Nguyen et al. where drug use and sexual risk behavior among male laborers were associated with psychological factors, social integration, and social barriers [13]. Having physical and mental health problems, in fact, have been found to be associated with unsafe sexual activity [38,39], which may cause psychosocial and cognitive impairment and reduce one's capacity to avoid engaging in risky behaviors [40].

Our findings emphasized the importance of implementing workplace-based health programs that focus on providing tailored education to prevent risky sexual behaviors. These programs should be free and targeted to promote condom use among industrial workers in Vietnam. As the majority of workers are low-wage and have limited formal education, these prevention programs should keep in mind the health literacy of workers and should approach workers and their families through broader public health messages. Additionally, an enhanced alcohol abuse screening program may help facilitate safe sex practices among workers. Such programs should be targeted at populations that are at higher risk of engaging in unprotected sexual activities, such as single male workers, migrant workers, and workers with mobility issues and/or self-care problems. A preliminary study evaluated the behavioral outcomes of an HIV counseling and testing service that integrated sexual and reproductive health services for young people living in industrial zones in Vietnam [41]. This study found that willingness to obtain an HIV test increased significantly and saw changes towards more positive knowledge, attitudes, and risk perception towards HIV/AIDS [41]. Results from our study also provided critical evidence for assessing sexual health risk behavior of industrial workers, which may help to promote national policies to meet the health care needs of this critical working population.

It should also be noted that our study has several limitations. First, the cross-sectional design constrained our ability to establish causal relationships regarding the associated factors and sexual risk behaviors. Second, convenience sampling may have reduced the generalizability of the study results to a larger factory worker population. In addition, our sample size of 230 factory workers from three different factories in Northern Vietnam may not have fully represented all factory workers in the country. Finally, self-reporting sensitive behaviors, such as alcohol use, self-care issues, mental illness, and risky sexual habits, may have been underreported due to the participants' social desirability and recall bias. These behaviors may be underreported due to a worker's fear of job loss or potential consequences about one's behaviors, despite this study's confidentiality and anonymity.

\section{Conclusions}

Our findings highlight the high percentage of workers in the sampled factories in Northern Vietnam who did not use condoms during their last sexual intercourse with sex workers and/or casual partners. Several characteristics that were associated with such risky sexual behavior included being immigrant and migrant workers, identifying as a binge drinker, and having mobility and self-care problems. Future workplace-based sexually transmitted infection prevention programs should focus on enhanced sexual education and promotion of safe sex practices among these high-risk populations. 
Author Contributions: Conceptualization, B.X.T., T.V., A.K.D., Q.N.N., C.A.L., and C.S.H.H.; Data curation, B.X.T., A.K.D., G.T.V., L.G.V., K.N.D., C.S.H.H., and R.C.M.H.; Formal analysis, Q.N.N. and G.T.V.; Investigation, T.V., A.K.D., and G.T.V.; Methodology, B.X.T., T.V., A.K.D., L.G.V., K.N.D., C.A.L., and R.C.M.H.; Project administration, B.X.T.; Software, L.G.V.; Supervision, B.X.T. and C.A.L.; Validation, Q.N.N., K.N.D., C.S.H.H., and R.C.M.H.; Visualization, G.T.V.; Writing—original draft, T.V., A.K.D., and Q.N.N.; Writing—review and editing, B.X.T., Q.N.N., C.A.L., C.S.H.H., and R.C.M.H.

Funding: This research received no external funding.

Acknowledgments: We would like to thank all workers in the three factories manufacturing electronics and vehicle accessories in Hanoi and Bac Ninh for supporting us in this study.

Conflicts of Interest: The authors declare no conflict of interest.

\section{References}

1. Coxhead, I.; Cuong, N.V.; Vu, L.H. Migration in Vietnam: New Evidence from Recent Surveys; Vietnam Development Economics Discussion Papers; World Bank: Hanoi, Vietnam, 2015.

2. Huang, W.; Dong, Y.; Chen, L.; Song, D.; Wang, J.; Tao, H.; Zaller, N.; Zhang, H.; Operario, D. Hiv risk and sexual health among female migrants in china. Health Promot. Int. 2016, 31, 595-605. [CrossRef] [PubMed]

3. Hargreaves, S.; Rustage, K.; Nellums, L.B.; McAlpine, A.; Pocock, N.; Devakumar, D.; Aldridge, R.W.; Abubakar, I.; Kristensen, K.L.; Himmels, J.W.; et al. Occupational health outcomes among international migrant workers: A systematic review and meta-analysis. Lancet Glob. Health 2019, 7, e872-e882. [CrossRef]

4. Al Rifai, R.; Nakamura, K.; Seino, K.; Kizuki, M.; Morita, A. Unsafe sexual behaviour in domestic and foreign migrant male workers in multinational workplaces in Jordan: Occupational-based and behavioural assessment survey. BMJ Open 2015, 5, e007703. [CrossRef] [PubMed]

5. Pham, K.T.H.; Nguyen, L.H.; Vuong, Q.H.; Ho, M.T.; Vuong, T.T.; Nguyen, H.T.; Vu, G.T.; Nguyen, H.L.T.; Tran, B.X.; Latkin, C.A.; et al. Health inequality between migrant and non-migrant workers in an industrial zone of vietnam. Int. J. Environ. Res. Public Health 2019, 16, 1502. [CrossRef] [PubMed]

6. Tuan, N.A.; Fylkesnes, K.; Thang, B.D.; Hien, N.T.; Long, N.T.; Kinh, N.V.; Thang, P.H.; Manh, P.D.; O'Farrell, N. Human immunodeficiency virus (hiv) infection patterns and risk behaviours in different population groups and provinces in viet nam. Bull. World Health Organ. 2007, 85, 35-41. [CrossRef]

7. Abdulkader, R.S.; Goswami, K.; Rai, S.K.; Misra, P.; Kant, S. HIV-Risk Behavior Among the Male Migrant Factory Workers in a North Indian City. Indian J. Community Med. Off. Publ. Indian Assoc. Prev. Soc. Med. 2015, 40, 108-115. [CrossRef]

8. Chamratrithirong, A.; Ford, K.; Punpuing, S.; Prasartkul, P. A workplace intervention program and the increase in HIV knowledge, perceived accessibility and use of condoms among young factory workers in Thailand. SAHARA J. 2017, 14, 132-139. [CrossRef]

9. Mucci, N.; Traversini, V.; Giorgi, G.; Garzaro, G.; Fiz Perez, J.; Campagna, M.; Rapisarda, V.; Tommasi, E.; Montalti, M.; Arcangeli, G. Migrant workers and physical health: An umbrella review. Sustainability 2019, 11, 232. [CrossRef]

10. Puri, M.; Cleland, J. Sexual behavior and perceived risk of hiv/aids among young migrant factory workers in nepal. J. Adolesc. Health Off. Publ. Soc. Adolesc. Med. 2006, 38, 237-246. [CrossRef]

11. Dai, W.; Gao, J.; Gong, J.; Xia, X.; Yang, H.; Shen, Y.; Gu, J.; Wang, T.; Liu, Y.; Zhou, J.; et al. Sexual behavior of migrant workers in Shanghai, China. BMC Public Health 2015, 15, 1067. [CrossRef]

12. Mondal, M.N.; Hoque, M.N.; Khan Chowdhury, M.R.; Moni, S.; Howard, J.; Rahman Choudhury, S. Risky Sexual Behaviors and HIV Vulnerability of Male Migrant Workers in Rajshahi City, Bangladesh. Epidemiol. Open Access 2014, 4, 160.

13. Nguyen, V.H.; Dunne, M.P.; Debattista, J.; Hien Nguyen, T.; Minh An Dao, T. Social Contexts of Risk Behaviors for HIV Among Male, Unskilled, Unregistered Laborers in Urban Vietnam. Qual. Health Res. 2011, 22, 871-879. [CrossRef] [PubMed]

14. Tran, A.N.; Nørlund, I. Globalization, industrialization, and labor markets in Vietnam. J. Asia Pac. Econ. 2015, 20, 143-163. [CrossRef]

15. Bradley, K.A.; DeBenedetti, A.F.; Volk, R.J.; Williams, E.C.; Frank, D.; Kivlahan, D.R. AUDIT-C as a brief screen for alcohol misuse in primary care. Alcohol. Clin. Exp. Res. 2007, 31, 1208-1217. [CrossRef] [PubMed] 
16. Tran, B.X.; Nguyen, H.L.T.; Le, Q.N.H.; Mai, H.T.; Ngo, C.; Hoang, C.D.; Nguyen, H.H.; Le, H.Q.; Van Nguyen, H.; Le, H.T.; et al. Alcohol and tobacco use among methadone maintenance patients in Vietnamese rural mountainside areas. Addict. Behav. Rep. 2018, 7, 19-25. [CrossRef] [PubMed]

17. Tran, B.X.; Ohinmaa, A.; Nguyen, L.T. Quality of life profile and psychometric properties of the EQ-5D-5L in HIV/AIDS patients. Health Qual. Outcomes 2012, 10, 132. [CrossRef]

18. Saggurti, N.; Verma, R.K.; Jain, A.; RamaRao, S.; Kumar, K.A.; Subbiah, A.; Modugu, H.R.; Halli, S.; Bharat, S. HIV risk behaviours among contracted and non-contracted male migrant workers in India: Potential role of labour contractors and contractual systems in HIV prevention. AIDS 2008, 22, S127-S136. [CrossRef]

19. Li, X.; Zhang, L.; Stanton, B.; Fang, X.; Xiong, Q.; Lin, D. HIV/AIDS-related sexual risk behaviors among rural residents in China: Potential role of rural-to-urban migration. AIDS Educ. Prev. 2007, 19, 396-407. [CrossRef]

20. Rojanapithayakorn, W. The $100 \%$ condom use programme in Asia. Reprod. Health Matters 2006, 14, 41-52. [CrossRef]

21. Hong, S.A.; Thepthien, B.-o. HIV risk-related sexual behavior by cohabiting partner status among factory workers: Results from the 2015 Bangkok behavioral surveillance survey (BSS). Cogent Soc. Sci. 2017, 3, 1364070. [CrossRef]

22. Hu, Z.; Liu, H.; Li, X.; Stanton, B.; Chen, X. HIV-related sexual behaviour among migrants and non-migrants in a rural area of China: Role of rural-to-urban migration. Public Health 2006, 120, 339-345. [CrossRef] [PubMed]

23. Ishtiaque, A.; Ullah, M.S. The Influence of Factors of Migration on the Migration Status of Rural-Urban Migrants in Dhaka, Bangladesh. Hum. Geogr. 2013, 7, 45-52. [CrossRef]

24. Yang, H.; Li, X.; Stanton, B.; Fang, X.; Lin, D.; Mao, R.; Liu, H.; Chen, X.; Severson, R. Workplace and HIV-related sexual behaviours and perceptions among female migrant workers. AIDS Care 2005, 17, 819-833. [CrossRef]

25. Wang, B.; Li, X.; Stanton, B.; Fang, X.; Liang, G.; Liu, H.; Lin, D.; Yang, H. Gender differences in HIV-related perceptions, sexual risk behaviors, and history of sexually transmitted diseases among Chinese migrants visiting public sexually transmitted disease clinics. AIDS Patient Care STDS 2007, 21, 57-68. [CrossRef]

26. Do, M.; Fu, H. Is women's self-efficacy in negotiating sexual decisionmaking associated with condom use in marital relationships in Vietnam? Stud. Fam. Plann. 2011, 42, 273-282. [CrossRef]

27. Bui, T.C.; Markham, C.M.; Ross, M.W.; Williams, M.L.; Beasley, R.P.; Tran, L.T.; Nguyen, H.T.; Le, T.N. Perceived gender inequality, sexual communication self-efficacy, and sexual behaviour among female undergraduate students in the Mekong Delta of Vietnam. Sex Health 2012, 9, 314-322. [CrossRef]

28. Tran, T.D.H.; Tuan, D.K.; Anh, N.D.; Le, T.K.A.; Bui, T.T.H. Premarital sex, contraceptive use among unmarried women migrant workers in industrial parks in Vietnam, 2015. Health Care Women Int. 2018, 39, 377-388. [CrossRef]

29. Wolffers, I.; Fernandez, I.; Verghis, S.; Vink, M. Sexual behavior and vulnerability of migrant workers for HIV infection. Cult. Health Sex. 2002, 4, 459-473. [CrossRef]

30. Tiruneh, K.; Wasie, B.; Gonzalez, H. Sexual behavior and vulnerability to HIV infection among seasonal migrant laborers in Metema district, northwest Ethiopia: A cross-sectional study. BMC Public Health 2015, 15, 122. [CrossRef]

31. Weine, S.M.; Kashuba, A.B. Labor migration and HIV risk: A systematic review of the literature. AIDS Behav. 2012, 16, 1605-1621. [CrossRef]

32. Chen, Y.; Li, X.; Zhang, C.; Hong, Y.; Zhou, Y.; Liu, W. Alcohol use and sexual risks: Use of the Alcohol Use Disorders Identification Test (AUDIT) among female sex workers in China. Health Care Women Int. 2013, 34, 122-138. [CrossRef] [PubMed]

33. Singh, S.K.; Schensul, J.J.; Gupta, K.; Maharana, B.; Kremelberg, D.; Berg, M. Determinants of alcohol use, risky sexual behavior and sexual health problems among men in low income communities of Mumbai, India. AIDS Behav. 2010, 14, S48-S60. [CrossRef] [PubMed]

34. Cooper, M.L. Alcohol use and risky sexual behavior among college students and youth: Evaluating the evidence. J. Stud. Alcohol Suppl. 2002, 14, 101-117. [CrossRef] [PubMed]

35. Fortenberry, J.D.; Orr, D.P.; Katz, B.P.; Brizendine, E.J.; Blythe, M.J. Sex under the influence. A diary self-report study of substance use and sexual behavior among adolescent women. Sex. Transm. Dis. 1997, 24, 313-319. [CrossRef] [PubMed] 
36. Li, Q.; Li, X.; Stanton, B. Alcohol use among female sex workers and male clients: An integrative review of global literature. Alcohol Alcohol. 2010, 45, 188-199. [CrossRef]

37. Tran, B.X.; Nguyen, L.H.; Nguyen, C.T.; Phan, H.T.; Latkin, C.A. Alcohol abuse increases the risk of HIV infection and diminishes health status of clients attending HIV testing services in Vietnam. Harm. Reduct. J. 2016, 13, 6. [CrossRef]

38. Carey, K.B.; Senn, T.E.; Walsh, J.L.; Scott-Sheldon, L.A.; Carey, M.P. Alcohol Use Predicts Number of Sexual Partners for Female but not Male STI Clinic Patients. AIDS Behav. 2016, 20, S52-S59. [CrossRef]

39. Khan, M.R.; Kaufman, J.S.; Pence, B.W.; Gaynes, B.N.; Adimora, A.A.; Weir, S.S.; Miller, W.C. Depression, sexually transmitted infection, and sexual risk behavior among young adults in the United States. Arch. Pediatr. Adolesc. Med. 2009, 163, 644-652. [CrossRef]

40. Rao, U. Links between depression and substance abuse in adolescents: Neurobiological mechanisms. Am. J. Prev. Med. 2006, 31, S161-S174. [CrossRef]

41. Ngo, A.D.; Ha, T.H.; Rule, J.; Dang, C.V. Peer-based education and the integration of HIV and Sexual and Reproductive Health services for young people in Vietnam: evidence from a project evaluation. PLoS ONE 2013, 8, e80951. [CrossRef]

(C) 2019 by the authors. Licensee MDPI, Basel, Switzerland. This article is an open access article distributed under the terms and conditions of the Creative Commons Attribution (CC BY) license (http://creativecommons.org/licenses/by/4.0/). 